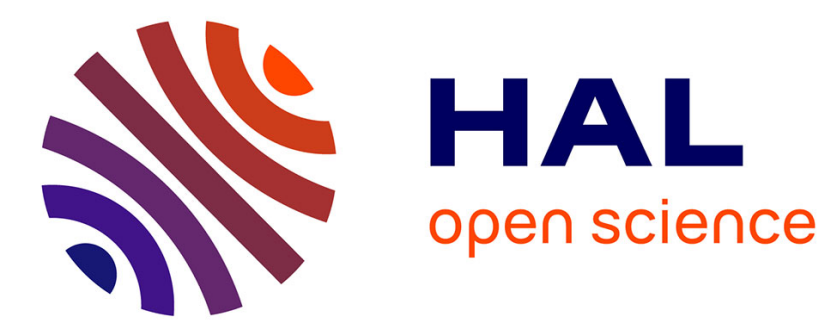

\title{
Design Strategies for Gridshells with Singularities
}

Ricardo Maia Avelino, Olivier Baverel, Arthur Lebée

\section{To cite this version:}

Ricardo Maia Avelino, Olivier Baverel, Arthur Lebée. Design Strategies for Gridshells with Singularities. Journal of the International Association for Shell and Spatial Structures, 2019, 60 (3), pp.189-200. 10.20898/j.iass.2019.201.023 . hal-02888490

\section{HAL Id: hal-02888490 \\ https://hal-enpc.archives-ouvertes.fr/hal-02888490}

Submitted on 3 Jul 2020

HAL is a multi-disciplinary open access archive for the deposit and dissemination of scientific research documents, whether they are published or not. The documents may come from teaching and research institutions in France or abroad, or from public or private research centers.
L'archive ouverte pluridisciplinaire HAL, est destinée au dépôt et à la diffusion de documents scientifiques de niveau recherche, publiés ou non, émanant des établissements d'enseignement et de recherche français ou étrangers, des laboratoires publics ou privés. 


\title{
DESIGN STRATEGIES FOR GRIDSHELLS WITH SINGULARITIES
}

\author{
Ricardo MAIA AVELINO', Olivier BAVEREL ${ }^{2}$, Arthur LEBÉE ${ }^{3}$ \\ ${ }^{1} \mathrm{MSc}$. Student at École des Ponts Paristech. \\ Email: ricardo.maia-avelino@eleves.enpc.fr \\ ${ }^{2}$ Pr., Laboratoire Navier, UMR 8205, École des Ponts ParisTech, IFSTTAR, CNRS, Université Paris Est. \\ Email: olivier.baverel@enpc.fr \\ ${ }^{3} \mathrm{Dr}$, Researcher, Laboratoire Navier, UMR 8205, École des Ponts ParisTech, IFSTTAR, CNRS, Université Paris Est. \\ Email: arthur.lebee@enpc.fr
}

Editor's Note: This space reserved for the Editor to give such information as date of receipt of manuscript, date of receipt of revisions (if any), and date of acceptance of paper. In addition, a statement about possible written discussion is appended.

DOI: Digital Object Identifier to be provided by Editor when assigned upon publication

\section{ABSTRACT}

This article discusses design strategies to improve the mechanical behavior of elastic gridshells with singularities. The advantage of meshing with one or more singularity is to allow a wider range of surfaces to be meshed with equal-length, quadrilateral meshes, known as Chebyshev nets. However, the application of this meshing process will influence the fabrication and the mechanical behavior of the structures. The erection process is simulated by means of the dynamic relaxation method, bending the bars to their final position. This simulation shows that a facetted shape is found instead of a smooth surface. This deformed shape makes the structure softer under applied gravity load. Two strategies are investigated in this paper to enable the construction of gridshells with singularities. The first consists in extending the bars close to the singularities edge-lines to have a smother gridshell after the erection process. The second strategy applies post-tension cables to the patches to increase the local curvature in the faceted zones. Both strategies increase the stiffness and buckling load of the final structure.

Keywords: Gridshells, Singularity, Composite Structures, Nonlinear analysis, Compass Method, Dynamic Relaxation, form-finding, post-tensioning.

\section{INTRODUCTION}

Gridshells are complex structures with an interesting potential to achieve innovative architectural forms [1]. These structures have the shape and stiffness of a double curvature shell; however, they are made of beam elements instead of a continuous surface [2]. As in shell structures, the main advantage of gridshells is that stresses acting on the structure are mainly transmitted through compression and traction, instead of bending.

These structures can be categorized in rigid and elastic gridshells and the main difference is related to the members' continuity [3]. The first structures are composed by discretized elements joined at nodes prefabricated with a specific length and orientation, as the Great Court gridshell at the British Museum [4]. Elastic gridshells are formed by continuous flexible elements [5] deformed elastically to match a target shape as in the Mannheim Bundesdartenschau [6]. The two structures are compared in [7] and depicted in Figure 1 .

Gridshells were introduced in 1962 by Frei Otto in the Essen prototype [8] and later extended to the ambitious the design in Mannheim. The technique raised further interest in the past decade with realization of multiple projects [9-10-11-12-13-14]. It should be noted that Frei Otto's original concept is linked to our classification of Elastic Gridshells in which the shape exploration is achieved by the deformation of a flat grid, either by erection [15] or by placing the elements over a forming shape [3]. 

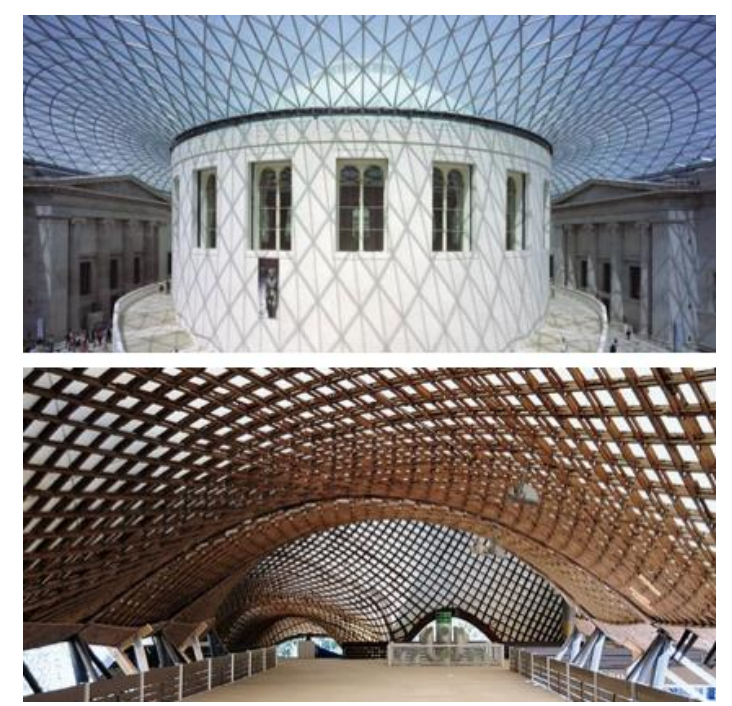

Figure 1. British Museum (top) and Manheim gridshell (bottom). (Photos by Foster+Partners and H. Berberich)

The meshing process of these structures create the system of bars that will compose the structure. Many strategies can be used to generate these grids one of them being the generation of Chebyshev meshes that are composed exclusively by equal-length quadrilaterals. Masson [16] demonstrated the limitations of this meshing process. The existence of Chebyshev nets is only ensured for surfaces with absolute total Gaussian curvature inferior to $2 \pi$. To overcome such a restriction the mesh can be divided in patches joined by singular points, also called singularities [17]. A singularity is a point with unique connection in the mesh (Figure 4).

The aim of this paper is to investigate the structural behavior of gridshells featuring singularities and to suggest strategies to predict and control their behavior.

The organization of the paper is as follows. In Section 2, Chebyshev nets are defined and the advantages of adding singularity points are discussed. Section 3 introduces the case study where two meshes featuring singularities are constructed and analyzed by means of a dynamic relaxation calculation. In Sections 4 and 5 two alternatives are suggested to improve the mechanical behavior of the previously created singular meshes. The first solution presented in Section 4 will be the extension of bars close to the edge-lines. The second solution presented in Section 5 introduces post-tension cables to enforce "fold lines" around the singularity. Finally, Section 6 summarizes the conclusions of the present study and suggests future work in the subject.

\section{CHEBYSHEV NETS AND MESHES}

The classical construction process of elastic gridshells is as follows. First, the structure is assembled on the ground being composed of an unbraced flat regular grid of beams connected with spherical joints. This grid may be freely sheared in its plane. Hence it is possible to deform the grid to obtain a 3D surface. Once the target shape is reached, the grid is braced to stiffen the final structure [6].

Predicting the achievable shapes with this construction process is a difficult form-finding problem. In the design of the Mannheim gridshell [6] members were assumed having zero bending stiffness, so the target surface was found as a hanging chain system. Earlier constructions tended to diverge from the zero bending stiffness method as in an overview by [3].

After defining the shape, an arrangement of the bars should be found realizing the gridshell. This paper focus in the generation of Chebyshev meshes for constructing these grids, these are composed by quadrilaterals with equal length and a classical method to find such meshes in a given surface is called compass method [2-5-13]. Starting from two master curves crossing themselves on the surface it is possible construct sequentially the equal-length rhombi forming the mesh. The mesh may reach the boundary of the surface or may stop early if a rhombus reaches a minimum predefined angle (Figures 2-3).

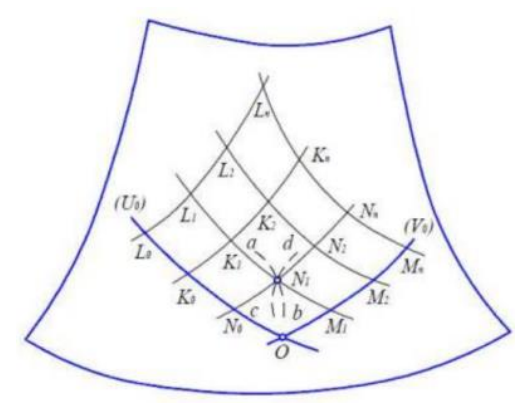

Figure 2. Compass method [2].

Hence, the existence of a Chebyshev net is not always guaranteed. It was proven that the existence is only ensured for surfaces whose total Gaussian curvature do not exceed $2 \pi$ as in [16] improving results from [18]. The limitation of the compass method was also treated by the original publication of Frei Otto [19] (Figure 3). 

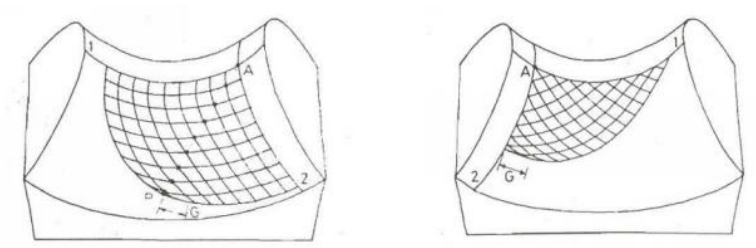

Figure 3. Limitations of the compass method in a torus surface [19].

An alternative strategy to mesh a higher diversity of surfaces was suggested by Masson [17] as the introduction of singularities in the network (Figure 4). The strategy of creating a singularity allows the designer to create patches in the surface which are separated by edge-lines (Figures 6-7-8).

The number of edge-lines converging to a singularity determine its valence $v$ and for most of the cases, the singularity index $i$ can be computed as: $i=1-v / 4$

(i)

(ii)

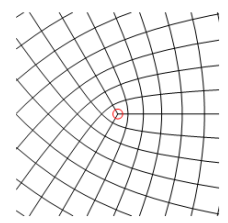

(iii)

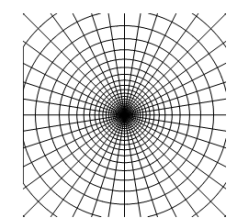

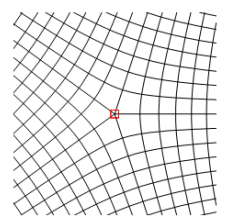

Figure 4. Singularity of indice (i) 1/4, (ii) -1/4, (iii) 1 [20]

Bunin [20] showed that the sum of the singularities' indices in a parametrization of a surface is related to its total Gaussian curvature. The advantages of introducing singularities are exemplified by Ghys [21] creating a Chebyshev net on a sphere (Figure 5) by placing two pole singularities that have index 1 . Equation 1 does not apply to calculate this index and the reader is referenced to a more general method considering the orientation of the faces as in [22].

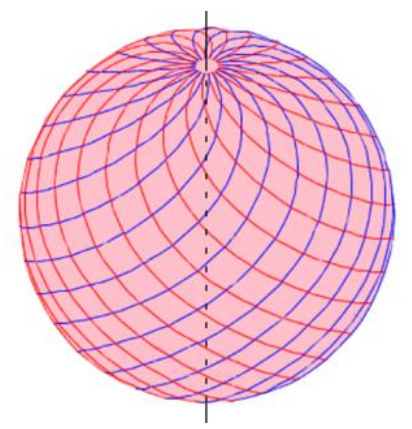

Figure 5. Sphere with two pole singularities [21].
All meshes presented in this article will be created using a C++ library interfaced with Grasshopper ${ }^{\circledR}$ implemented by Masson [17]. This Grasshopper component applies the compass method to $n$ curves and in a given surface. It allows also for the creation of pole singularities by defining a dual curve and the density of rhombi that should be present in that curve. A few examples are depicted (Figures 6-7-8).
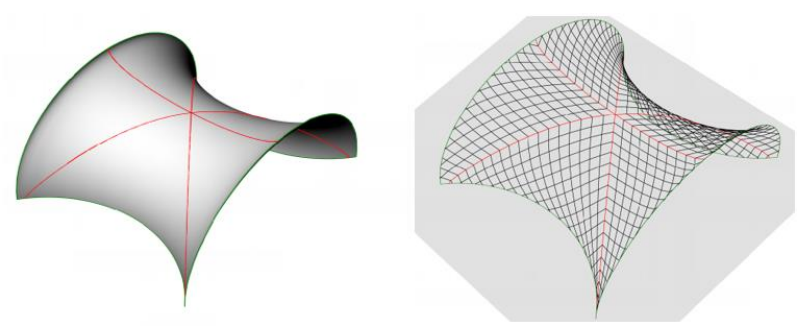

Figure 6. Meshing Torus surface with a singularity of valence 6.

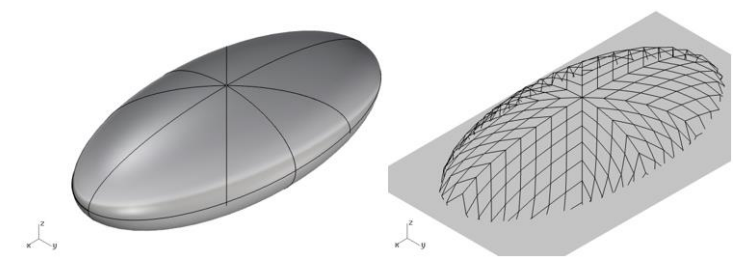

Figure 7. Meshing Ellipsoid with a singularity of valence 8

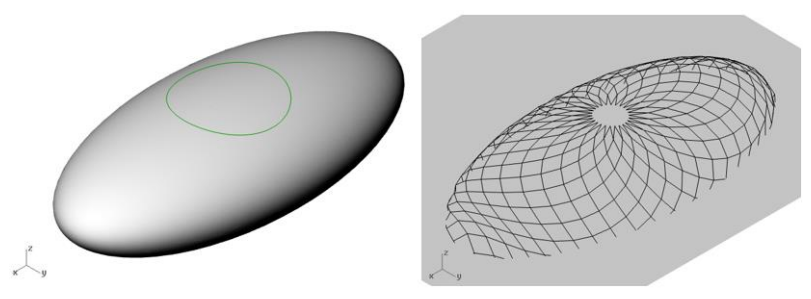

Figure 8. Meshing Ellipsoid with a pole singularity

\section{ANALYSIS OF GRIDSHELLS WITH SINGULARITIES}

\subsection{Reference gridshell}

The aim of this paper is to compare the form-finding process and the structural behavior of a gridshell including singularities with an already existing gridshell structure designed and built by Laboratoire Navier. The reference gridshell was designed for the Solidays' Festival in 2011 (Figure 9). 

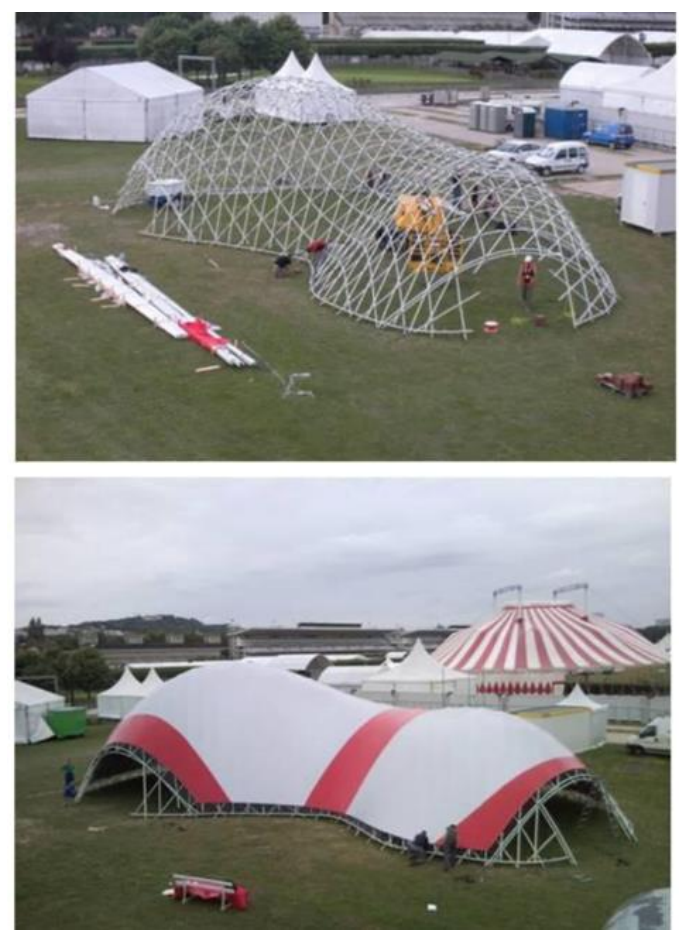

Figure 9. Structural grid achieved and braced (top). Final design of Solidays gridshell (bottom) [23].

The structure had a peanut shape and was constructed close to Paris, as a shelter for 500 people. It spanned approximately $10 \mathrm{~m} \times 25 \mathrm{~m}$ and was $7 \mathrm{~m}$ high at the top. The structure was composed of a grid of $3 \mathrm{~mm}$ thick GFRP tubes with $42 \mathrm{~mm}$ diameter braced with a third layer made with the same tubes [10] (Figure 10).

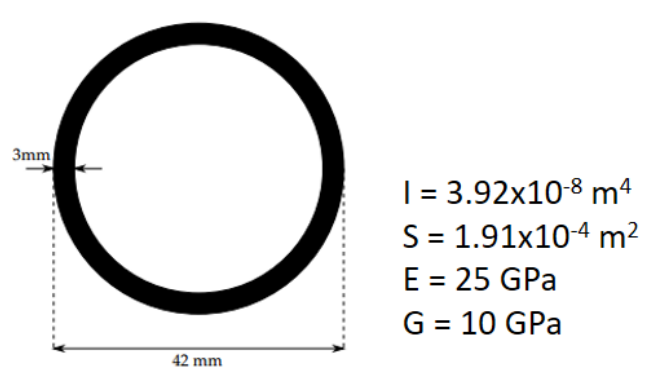

Figure 10. Material and Cross section properties of the gridshell beams [15].

\subsection{Meshes with singularities}

In this paper, the original mesh is compared with two different mesh-designs. These meshes have a singularity of valence 6 which creates 6 patches limited by 6 edge-lines (Figure 12).

As discussed in Section 2, since the existence of Chebyshev nets is related to the Gaussian curvature and its integral over the target surface, the extreme values of Gaussian curvature will be considered as hotspots for placing singularities.

The first region in Figure 11 will host the singularity for mesh A since it is the one with the largest positive Gaussian curvature. Conversely, the second region will host a singularity for mesh B since it is the region with minimal Gaussian curvature. It is also the weakest point of the structure and the flattest area in the gridshell. Indeed, previous works [24-25] showed that this was the maximum displacement zone and the region where the maximum axial stress was found in the reference project (Figure 9).

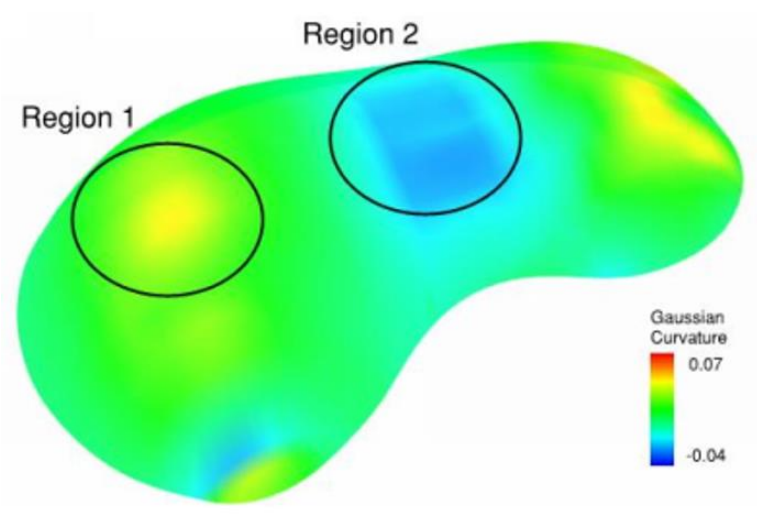

Figure 11. Gaussian curvature analysis of Solidays' original surface
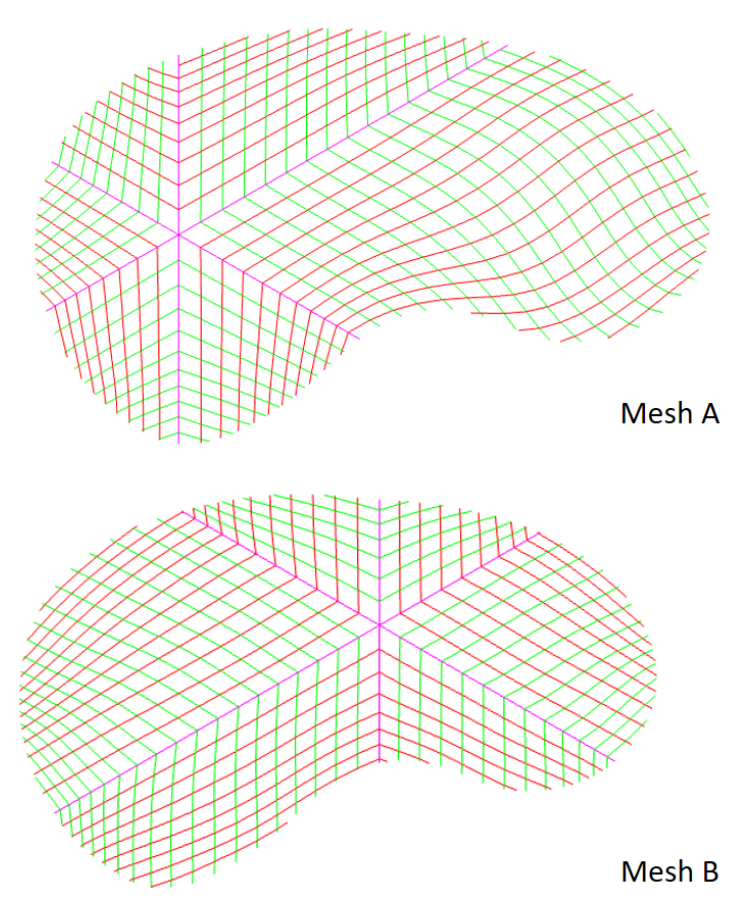

Figure 12. Top view of the $3 D$ meshes $A$ and $B$ 
Once the target mesh is defined, the structure is analyzed in two steps. First, the forming step, which corresponds to the bending of the initially straight beams to reach a $3 \mathrm{D}$ surface, is performed through a dynamic relaxation analysis (DR). Second, the relaxed structure is braced and analyzed under external loads through a non-linear FEM analysis.

\subsection{Dynamic relaxation (DR) analysis}

The forming step is simulated by imposing a prestress in the bars corresponding to the curvature of the initially straight bars once forced into the geometry of the meshes in Figure 12. In addition, the boundary condition blocks the displacement of ground points. The connection between bars allows the relative rotation perpendicular to the tangent plane. Bars are continuous in each patch and are considered having only 3 translational d.o.f. per node [9] not accounting for rotational effects as in [26].

The DR method searches for the final geometry of the structure by a dynamic formulation of the equilibrium equations considering the energy stored in the bars [27]. During the analysis, the structure oscillates until it reaches the minimum potential energy [9]. Artificial damping of the structure is introduced to reach faster the equilibrium [28]. The software used to perform DR calculations is the v4.0 of a Grasshopper plugin developed in C\# by Lionel du Peloux [29] and validated during his PhD Thesis.

By looking at the deformed shape of meshes A and B (Figure 13), one can conclude that the original target geometry was not achieved. Indeed, the structure presents a facetted final form which resembles a polyhedral structure. There is no more visual continuity of the tangent plane on the edgelines that separate the different patches.

\subsection{FEM analysis for external loads.}

A geometrically non-linear FEM analysis is performed with the software Karamba ${ }^{\circledR}$ to assess the final behavior of the structure. For this analysis, the initial geometry is extracted from the DR step (Figure 13) and the structure is braced (Figure 14).

The bracing system is added to the meshes as a third layer of bars. The strategy applied in this paper (Figure 14) sets a two-directions bracing system previously applied in [30] for all meshes except for Mesh E (Figure 21) as it will be discussed later in Section 5. The bracing members can work in traction as well as in compression and, similarly to the project of reference, they keep the same properties as the grid members (Figure 10). To enhance the visualization of the meshes in this article, the bracing system is commonly hidden in the figures presented. Other bracing strategies as applied in [12-13] are not studied in this article.
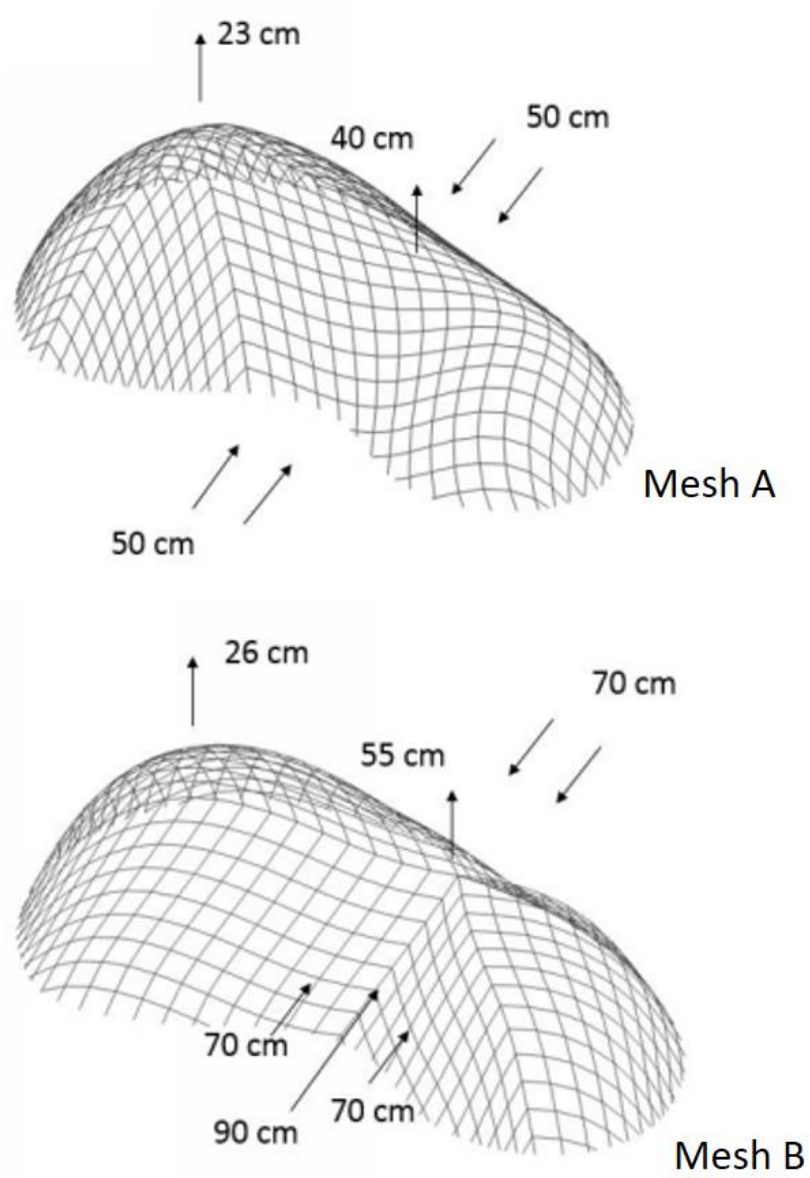

Figure 13. Meshes $A$ and $B$ after relaxation.

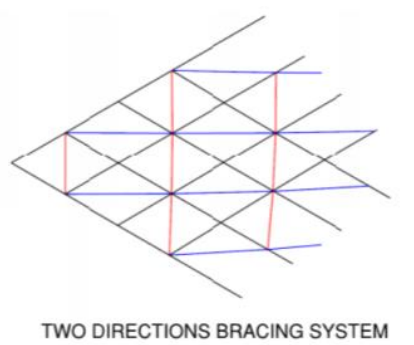

Figure 14. Two direction bracing system applied.

The braced mesh geometry is used as reference configuration in the FEM Model. All links between bars are modeled as rigid connections. All displacements are restrained at the boundary of the gridshell. The sections remain the same (Figure 10). 
Table 1. FEM Analysis of all meshes

FEM study for $F=30 \mathrm{kN}$ with all meshes of the paper

\begin{tabular}{ccccccc}
\hline Mesh & $\begin{array}{c}\text { Max. disp. } \\
(\mathbf{m})\end{array}$ & $\begin{array}{c}\text { E-Axial } \\
(\mathbf{k N m})\end{array}$ & $\begin{array}{c}\text { E-Bending } \\
(\mathbf{k N m})\end{array}$ & $\begin{array}{c}\text { E-Total } \\
(\mathbf{k N m})\end{array}$ & $\begin{array}{c}\text { \% Axial } \\
\mathbf{\%}\end{array}$ & $\begin{array}{c}\text { Linear Buckling } \\
(\mathbf{k N})\end{array}$ \\
\hline Mesh A & 0.023 & 0.027 & 0.014 & 0.041 & $65 \%$ & 82 \\
\hline Mesh B & 0.024 & 0.025 & 0.020 & 0.045 & $55 \%$ & 195 \\
\hline Mesh C & 0.019 & 0.031 & 0.007 & 0.038 & $82 \%$ & 202 \\
\hline Mesh D & 0.019 & 0.030 & 0.006 & 0.037 & $82 \%$ & 184 \\
\hline Mesh E & 0.019 & 0.023 & 0.012 & 0.035 & $67 \%$ & 141 \\
\hline Mesh E + PT & 0.012 & 0.133 & 0.024 & 0.157 & $85 \%$ & 231 \\
\hline Original & 0.019 & 0.041 & 0.009 & 0.050 & $83 \%$ & 171 \\
\hline
\end{tabular}

The load case studied represents snow loading, modeled as nodal vertical forces applied on the upper part of the gridshell. The total snow load $\mathrm{F}$ is equal to $30 \mathrm{kN}$ corresponding to an average load of $10 \mathrm{~N} / \mathrm{m}^{2}$ in plane. This load is inferior to the loads applied to the real design [24], however it is chosen so that none of the examples buckles allowing for the comparison between the proposed systems. The bending energy stored in the beams during the forming process is neglected, this assumption was already made in [1531] and conducted to accurate results.

To validate our simulations with Karamba, the results of the original mesh were compared with previous calculations in the same mesh done in previous work [24] with the software GSA. The observed maximum displacement was $19 \mathrm{~mm}$ for 30 $\mathrm{kN}$ of applied load in our model (Table 1) and $18 \mathrm{~mm}$ in [24]. The linear buckling load for the Karamba model was $171 \mathrm{kN}$ (Table 1) and $206 \mathrm{kN}$ in [24]. The small differences $(<15 \%)$ and the operability in the parametric environment of Grasshopper encourage the adoption of Karamba as FEM engine herein.

The comparison between the original mesh of the structure and the relaxed meshes A and B reveals that they have displacements $20 \%$ larger than in the original structure (Table 1). Hence the singularity decreases the stiffness of the gridshell.

Moreover, the proportion of the axial energy (EAxial) decreased in the total elastic energy (E-Total) of the structure (Table 1). This is due to the nonsmooth final shape presented in Figure 13 which requires additional bending of the patches for achieving equilibrium. Regarding the buckling load, Mesh A presented a drastic reduction of $52 \%$ from $171 \mathrm{kN}$ to $82 \mathrm{kN}$ and Mesh B an increase of $14 \%$.
These observations lead us to reconsider the application of the singularity since the non-smooth shape after construction does influences the shell mechanical behavior of the structure. Two improvement strategies are investigated.

\section{FIRST IMPROVEMENT STRATEGY: EXTENSION OF GRIDSHELL BARS}

\subsection{Overview}

The first design strategy proposed is the extension of the bars adjacent to the edge-lines. These bars are extended beyond the edge-lines to intersect with the opposite vertex in the rhombi (Figure 15). The extension is always made in clockwise direction by extending bars of opposite colors in each patch (red and blue). This generates a seaming between the patches providing a continuity of the tangent planes between them. This concept recalls the solution adopted in nexorade structures [32].
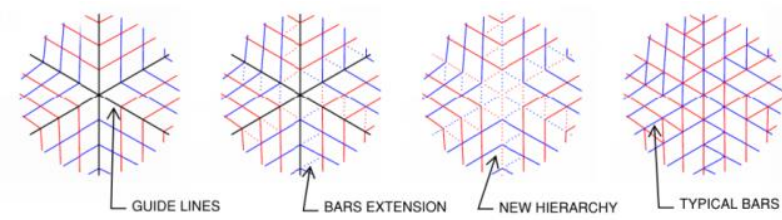

Figure 15. Procedure for extending the bars at edge-lines.

This strategy applied to mesh A is denoted mesh C, and when it is applied to mesh B, it generates mesh $\mathrm{D}$ (Figure 16). Note that, the extension requires the grid to be two-colorable and is limited to singularities with even valence since the bars to be extended must have the same color at a given edgeline. 


\subsection{Dynamic relaxation analysis}

The forming step is performed again for meshes $\mathrm{C}$ and $\mathrm{D}$ by means of the dynamic relaxation method. The results show that the nexorade connections in the gridshells bars is closer to the initial form. The relaxed mesh presents less global displacement and a smother shape (Figure 17). The strategy created stiffer areas along edge-lines, improving the stability of the gridshell.
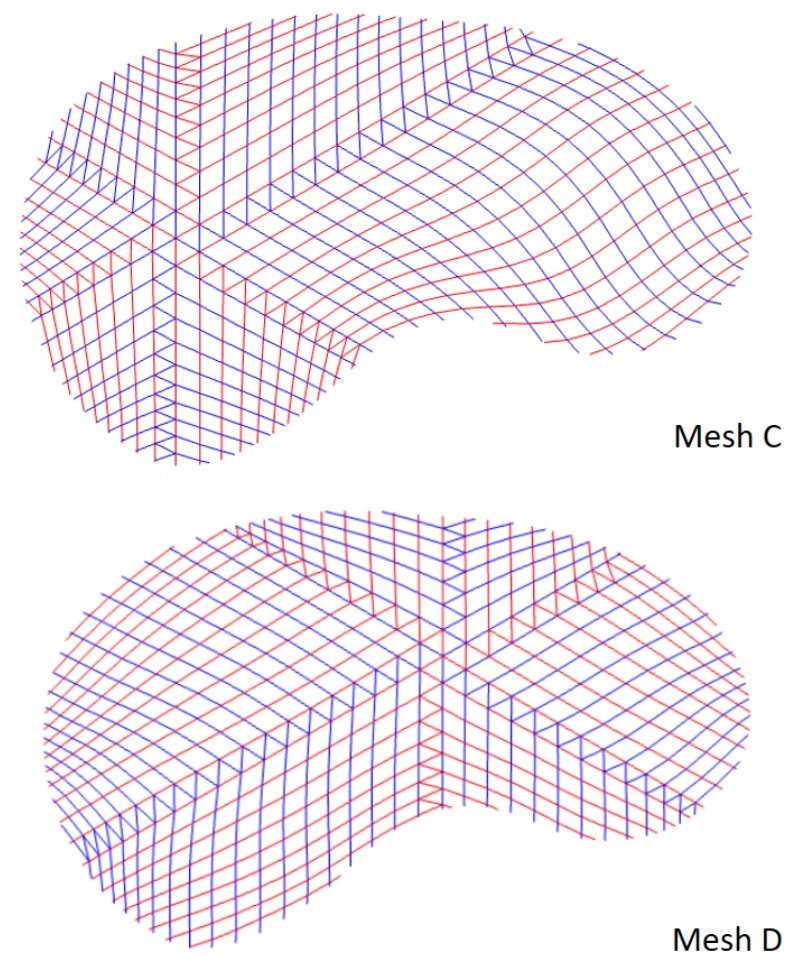

Figure 16. Proposed meshes $C$ and D

\subsection{FEM analysis for external loads.}

The same FE modelling as in Section 3.4 is performed. When comparing the results from the previous sections (Table 1), one can see that the strategy adopted not only reduced the deformation of the grid after the relaxation process but also improved the mechanical behavior of the meshes with singularities under external loads since the maximum deflection is reduced to $0.019 \mathrm{~m}$.

The portion of bending energy also decreased for meshes $\mathrm{C}$ and $\mathrm{D}$ comparing to meshes $\mathrm{A}$ and $\mathrm{B}$. This indicates that their shell behavior is improved.

\subsection{Directions of improvement}

The extension of the patches improved the stiffness of the gridshell and the smoothness of the shape. The patches also divide the grid in smaller parts easier to pre-assemble on site as suggested in [33]. Further studies should be performed to explore additional singularity positions and valences as in [22] and to guarantee the two-colorability of the grid.
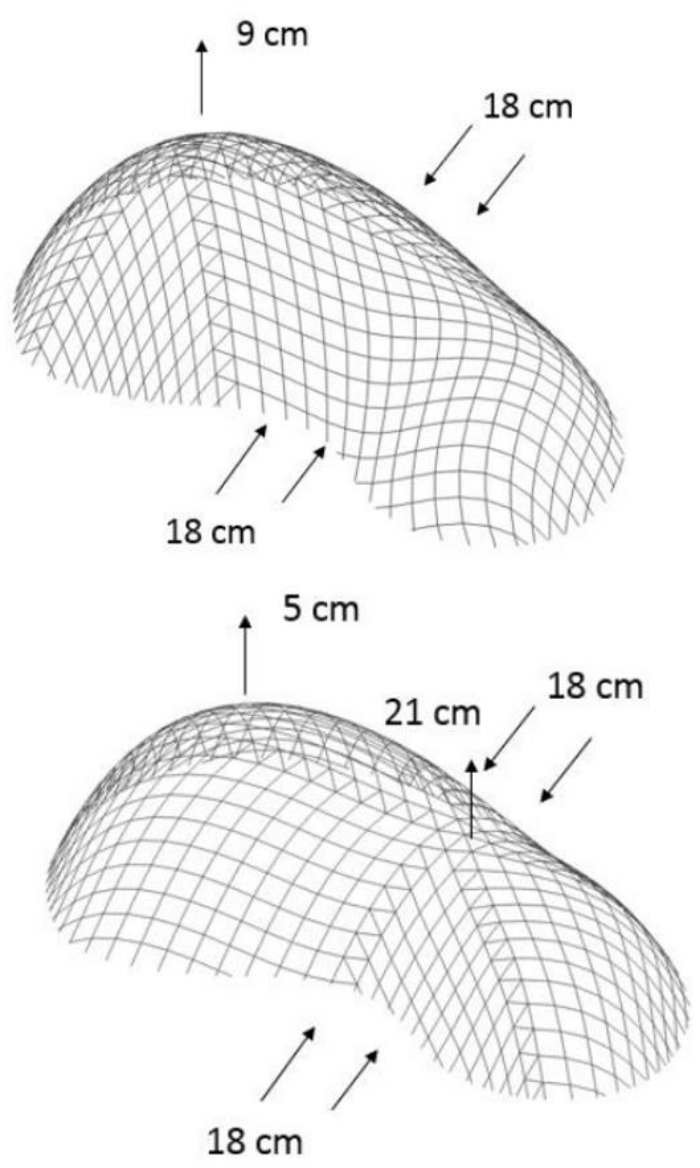

Figure 17. Dynamic relaxation applied to meshes $C$ and $D$.

\section{SECOND IMPROVEMENT STRATEGY: 'POST-TENSIONED GRIDSHELL' ELASTIC}

\subsection{Overview}

The second design strategy discussed in this article investigates "fold lines" around the singularities. It is based on post-tension cables placed in the interior of the gridshell. These cables are intended to increase locally the curvature of the structure that was lost during the relaxation phase of meshes $\mathrm{A}$ and $\mathrm{B}$. The strategy will be applied to mesh B that presents the largest deformations after the relaxation process.

The cables are added after the bracing system is placed. The following figures doesn't show the bracing layer to enhance the visualization. 


\subsection{Straight Cables PT}

The first proposition intends to connect points of two adjacent edge-lines. The post-tension forces are applied as shortening of the cables placed after the erection of the gridshell and after its bracing system installation (Figure 18).

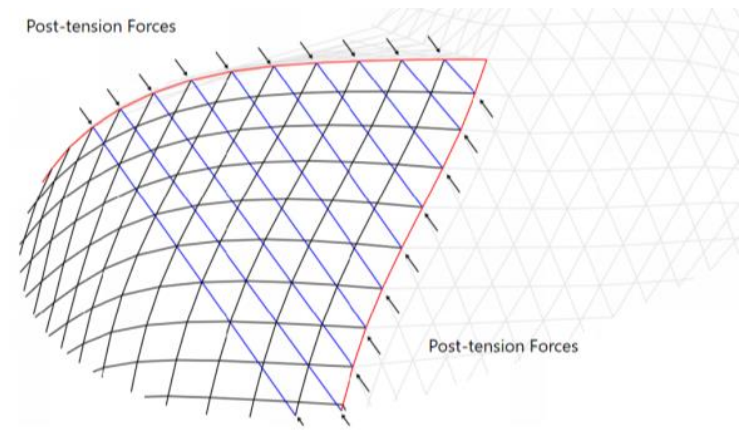

Figure 18. Straight cables solution connecting two edgelines. Bracing layer hidden for visualization purposes

\subsection{Fitted Cables PT}

The second proposition not only connects points of two adjacent edge-lines but also insert strut elements that will push out the structure and enforce a positive curvature in all regions. These elements are considered as additional members made of the same material and cross-section. The post-tension will also be applied after the erection of the gridshell and after bracing (Figure 19).

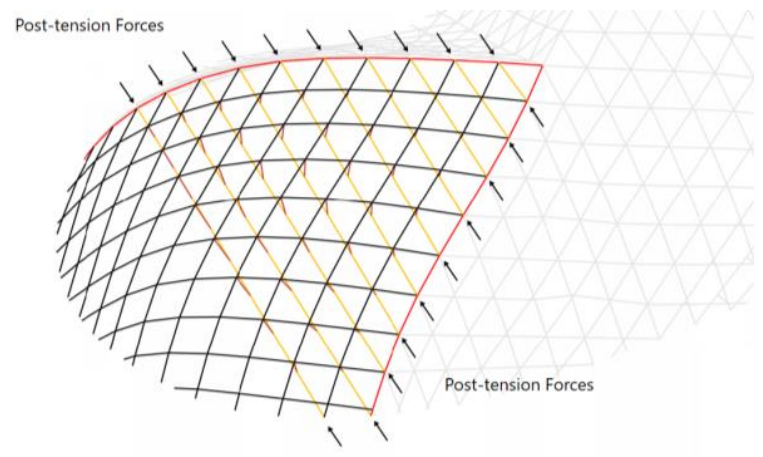

Figure 19. Fitted Cables solution connecting two edgelines and having strut elements. Bracing layer hidden for visualization purposes

Both strategies are not directly applicable to mesh B for two reasons. First, cables are exterior to the structure in areas where the Gaussian curvature is negative. Second, considerable differences of the patches size make the connection between the edgelines impossible. Hence, a specific meshing process is developed to enable the installation of PT cables.

\subsection{Proposed Mesh $E$ with multiple singularities}

A strategy is developed to create more suitable meshes to receive a PT system. These meshes should generate patches with similar sizes and adapt the singularity valence with the Gaussian curvature distribution. The objective is to avoid exterior cables and patches of different size.

This mesh strategy is applied to the geometry of Soliday's (Figures 9-11) following the steps described herein (Figure 20):

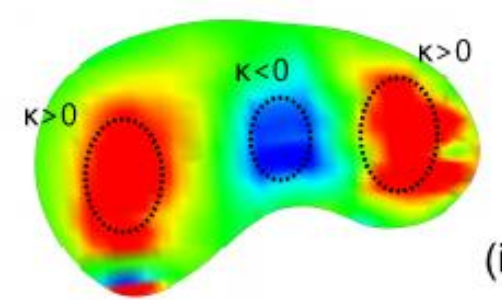

(i)

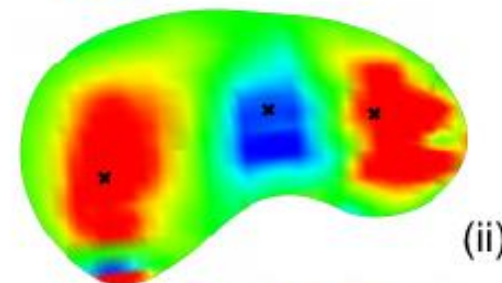

(ii)
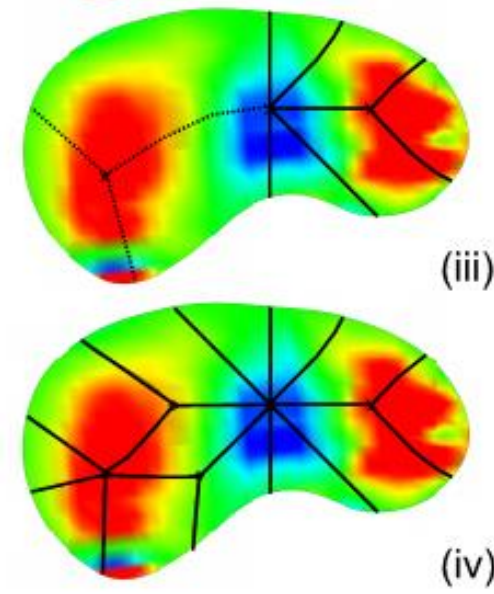

(iv)

Figure 20. Position of the singularities

(i). Find positive and negative extremes of curvature. (ii). Place singularities point on these regions.

(iii). Positive curvature regions receive singularities of valence 3 as in Voltera Constructions [20] while the valence of the singularity in negative regions is increased to avoid negative curvature on the patches. (iv). Generate patches with comparable size while introducing additional singularities. 
The mesh is then braced by a pattern centered in the negative curvature region. The final structure is composed by several different layers (Figure 21). It is important to remark that one of the patches is not connected to the boundaries of mesh E (Figure 22). If many of these patches exist, the designer should check the global stability of the gridshell and the Chebyshev net existence in the internal patch.

The Fitted Cables solution is applied to the mesh E (Figure 22). Due to the presence of strut elements and the meshing strategy applied, there are no cables exterior to the structure (Figure 24). When necessary the cables are deviated to be inside the structure.

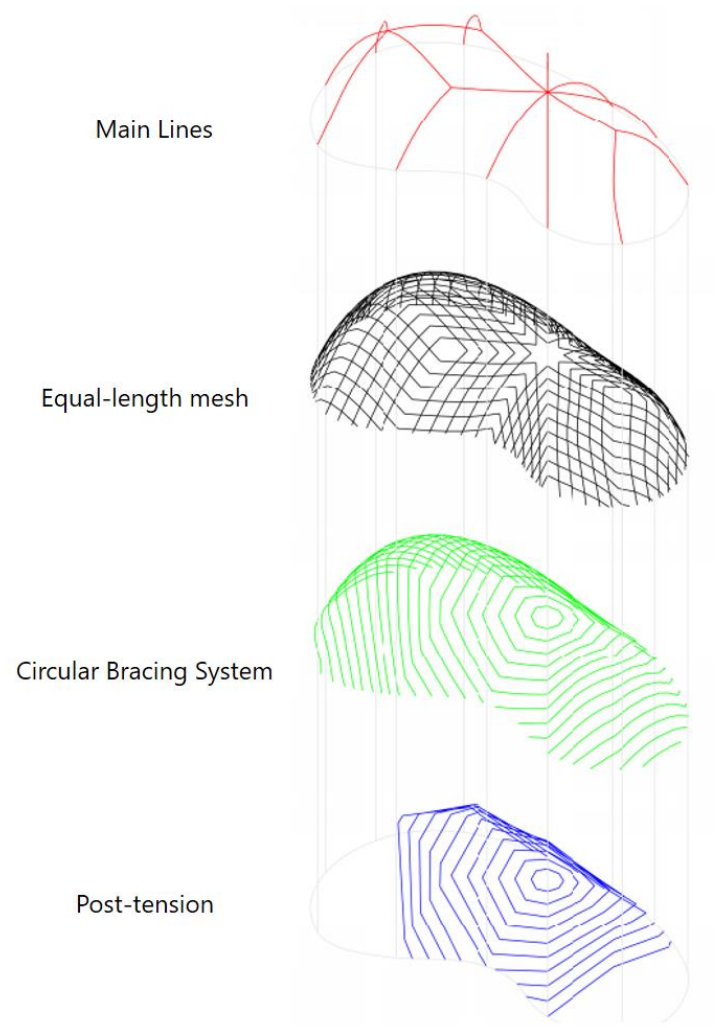

Figure 21. Overview of Layers at Mesh E

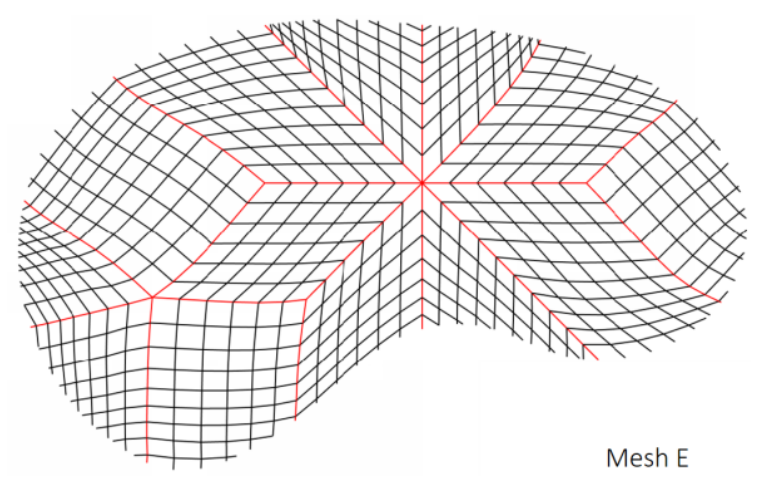

Figure 22. Mesh E final design

\subsection{Dynamic relaxation analysis on Mesh $\mathbf{E}$}

The forming step is performed on mesh E. The final shape of the structure is presented in Figures 23-24.

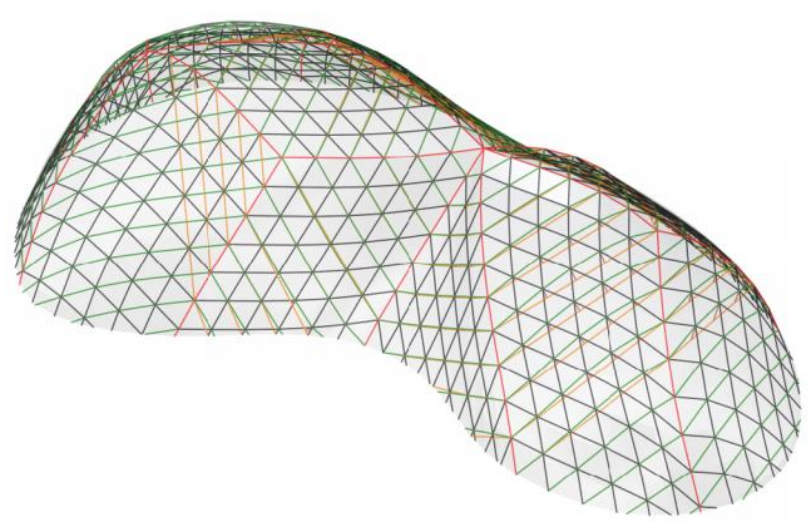

Figure 23. Relaxed Shape of Mesh E. After bracing system and fitted cables PT solution applied.

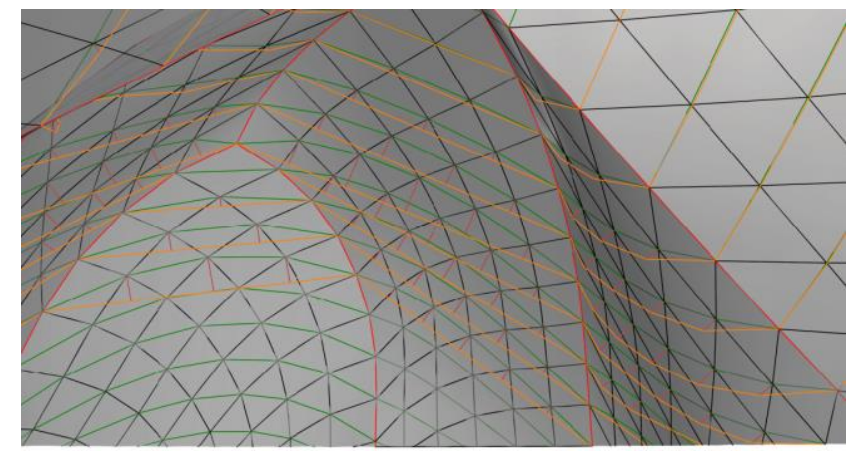

Figure 24. Perspective of the interior of Mesh E. showing the Fitted Cables solution inside.

\subsection{FEM Analysis with post-tension cables}

As in previous examples, a non-linear FEM analysis is performed keeping the same base assumptions. PT cables are made of steel S235 and assigned with a circular cross-section having diameter $D=1 \mathrm{~cm}$. The post-tension load is assigned as a negative axial deformation of the cables. This deformation is the same for all cables and it is set as $-0.5 \mathrm{~mm} / \mathrm{m}$. For the analysis with mesh $\mathrm{E}$, the fitted cables solution presented in 5.3 is applied.

The deflection results (Table 1) are presented for the case where the prestress is not added to the structure (Mesh E) and for the case in which $-0.5 \mathrm{~mm} / \mathrm{m}$ is assigned to the cables (Mesh E + PT). One can see that mesh $\mathrm{E}$ is as stiff as prolonged meshes $\mathrm{C}$ and $\mathrm{D}$ having a maximum displacement equals to $0.019 \mathrm{~m}$. However, it presents a buckling load inferior (141 
$\mathrm{kN}$ ) to the original structure's buckling load (Table $1)$.

Regarding mesh E with PT cables (Mesh + PT), it is observed that the maximum displacement for this mesh under gravity load case applied is lower than the maximum displacement obtained with the original structure. Furthermore, this solution increases the bucking load from $141 \mathrm{kN}$ to $231 \mathrm{kN}$, which is the highest buckling load (Table 1).

\subsection{Directions of improvement}

The second adopted strategy improved buckling and stiffness of the original grid. However, the introduction of the strut elements and the posttensioned cables increased the complexity of the gridshell. Other combinations in order to apply the post-tension and bracing might also be investigated. For instance, post-tension could be applied to the unbraced structure followed by bracing and possibly the removal of the post-tensioning elements after the shape is locked. This technique is only applied to the facetted structures, and the potential benefits of introducing these cables in a smooth structure (such as the original mesh) was not verified.

Another alternative to enhance post-tensioning on the patches could be applying it to adapted shapes and meshes as for instance in the half-dome of Figure 25. featuring symmetry and positive curvature facilitating the placement of the PT cables.
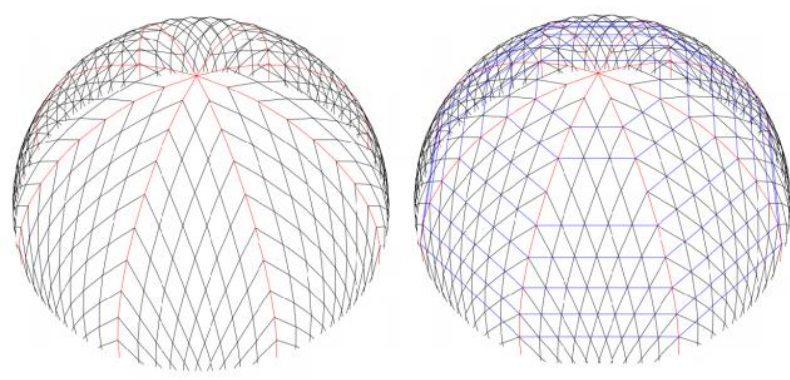

Figure 25. Half dome with singularity of valence 8 (left) and after installation of post-tensioned cables (right).

\section{CONCLUSION}

The introduction of singularities enables the designer to generate a wide variety of meshes. In this article, the forming steps of five different meshes were simulated where the bars of the elastic gridshell are bent to match a target shape.
The introduction of a singularity creates edge-lines and after the deformation of the initially flat grid, these edges revealed a faceted final shape observed in meshes A and B. These structures were less stiff than the original configuration and presented higher percentage of bending elastic energy. For that reason, additional strategies in the design, fabrication and construction of such structures have to be taken in consideration.

Two design strategies were suggested to explore gridshells with singularities:

A first strategy consisting in extending patches was applied and resulted in stiffer meshes that responded better to the target shape proposed in this paper and presented a better shell behavior with more membrane elastic energy. Further development of this technique should focus in achieving twocolorable patterns and rationalizing the form of the patches. A sensitivity study in the extension length of the bars could also elucidate its relationship with the smoothness and stiffness of the final shape.

A second strategy consisting in post-tensioning applied underneath the original grid was suggested creating a post-tensioned gridshell. This strategy could not be applied to any type of initial mesh. A new meshing process was discussed, and the posttensioned structure presented a higher stiffness and buckling load. The post-tensioned gridshell could be brought to a real scale prototype considering specific meshes that would facilitate the placement of the cables. Additionally, the order of the post-tensioning and bracing system might also be further studied.

The structural and architectural potential of gridshells with one or multiple singularities seems promising. The authors intend that the ideas presented in this work encourage further investigation in the field.

\section{ACKNOWLEDGEMENTS}

The authors thank Yannick Masson for providing the meshing tool used to create the Chebyshev networks with singularities and Lionel du Peloux for providing the dynamic relaxation tool used to perform DR calculations on the various structures. We also thank the valuable commentaries and ideas of the reviewers that improved substantially the present work. 


\section{REFERENCES}

[1] R. Mesnil, "Structural explorations of fabrication-aware design spaces for nonstandard architecture," Ph.D. dissertation, Université Paris Est, Marne la Vallée, 2017. (Online: $\quad$ https://hal-enpc.archivesouvertes.fr/tel-01510053)

[2] L. Bouhaya, "Optimisation structurelle des gridshells," Ph.D. dissertation, Université Paris Est, Marne la Vallée, 2010. (Online : https://tel.archives-ouvertes.fr/tel-00583409/)

[3] D. Naicu, R. Harris and C. Williams, "Timber Gridshells: Design methods and their application to a temporary pavilion" World Conference on Timber Engineering, Quebec City, Canada, 2014.

[4] J. Sischka, "Engineering the construction of the great court roof for the British Museum" in Widespan Roof Structures, Thomas Telford, pp. 199-207, 2000. (DOI: https://doi.org/10.1680/wrs.28777.0021 )

[5] L. Du Peloux, F. Tayeb, O. Baverel and JF. Caron, "Faith Can Also Move Composite Gridshells," in Proceedings of IASS Annual Symposia, IASS 2013 Wroclaw: 'Beyond the Limits of Man', Wroclaw, Poland, 23-27 September, 2013.

[6] E. Happold and W. Lidell, "Timber lattice roof for the Mannheim Bundesgartenschau," The Structural Engineer, Vol. 53 Issue 3, 99135, 1975.

[7] C. Williams, "The Multihalle and the British Museum: A comparison of two gridshells," in Shell structure for architecture: Form finding and optimization, S. Adriaenssens, P. Block, D. Veenendaal, and C. Williams, eds., Routledge, New York, 239-246, 2014. (DOI: https://doi.org/10.4324/9781315849270)

[8] I. Liddell, "Frei Otto and the development of gridshells," Case Studies in Structural Engineering, Vol. 4, pp-39-49, 2015 (DOI: https://doi.org/10.1016/j.csse.2015.08.001)

[9] S. Adriaenssens and M. R. Barnes, "Tensegrity spline beam and grid shell structures," Engineering Structures, Vol. 23,
No. 1, pp. 29-36, 2001. (DOI: https://doi.org/10.1016/S01410296(00)00019-5)

[10] O. Baverel, JF. Caron, F. Tayeb and L. Du Peloux, "Gridshells in composite materials: construction of a $300 \mathrm{~m} 2$ forum for the solidays' festival in Paris," Structural Engineering International, Vol. 22, No. 3, pp. 408-14, 2012.2 (DOI: https://doi.org/10.2749/101686612X1336386 9853572)

[11] E. Lafuente Hernández, "Design and optimisation of elastic gridshells," Ph.D. dissertation. Universität der Künste Berlin, Berlin, $2015 . \quad$ (Online: https://opus4.kobv.de/opus4udk/frontdoor/index/index/year/2016/docId/9 94)

[12] R. Harris, S. Haskins and J. Roynon, "The Savill Garden gridshell: design and construction", The Structural Engineer, Vol. 86, No.17, pp. 27-34, 2008.

[13] R. Harris, J. Romer, O. Kelly and S. Johnson, "Design and construction of the Downland gridshell", Building Research and Information, Vol. 31, No. 6, pp. 427-454, 2003.

(DOI: https://doi.org/10.1080/09613210320000880 07)

[14] S. R. Malek, "The effect of geometry and topology on the mechanics of grid shells," $\mathrm{PhD}$ dissertation. Massachusetts Institute of Technology, Cambridge, 2012. (Online: https://dspace.mit.edu/handle/1721.1/74425 )

[15] R. Mesnil, "Stability of Elastic Grid Shells," Master Thesis, Massachusetts Institute of Technology, Cambridge 2013. (Online: https://dspace.mit.edu/handle/1721.1/82716 )

[16] Y. Masson and L. Monasse, "Existence of global Chebyshev nets on surfaces of absolute Gaussian curvature less than $2 \pi$," Journal of Geometry, Springer Verlag, Vol. 108, No 1, pp.25-32, 2016.2 (DOI: https://doi.org/10.1007/s00022-016-0319-1 )

[17] Y. Masson, "Existence et construction de réseaux de Chebyshev avec singularités et 
application aux gridshells," $\mathrm{Ph}$.D. dissertation, Université Paris-Est, Marne la Vallée, 2017. (Online :

http://www.theses.fr/2017PESC1144 )

[18] S. L. Samelson and W. P. Dayawansa, "On the existence of global Chebyshev nets," Trans. Am. Math. Soc., Vol. 347, pp. 651-660, 2012. (DOI: https://doi.org/10.1007/s00022-0160319-1)

[19] IL10 Gitterschalen. Institut für leichte Flächentragwerke (IL), 1974.

[20] G. Bunin, "A continuum theory for unstructured mesh generation in two dimensions", Comp. Aided Geom. Des., Vol. 25, No. 1, pp.14-40, 2008. (DOI: https://doi.org/10.1016/j.cagd.2007.05.002)

[21] E. Ghys, "On the cutting of garments: variation on a theme of Chebyshev," Enseign. Math, Vol. 57, No. 1-2, pp.165-208, 2011.

[22] R. Oval, M. Rippmann, R. Mesnil, T. Van Mele, O. Baverel and P. Block, "Featurebased Topology Finding of Patterns for Shell Structures," Automation in Construction, Vol. 103: $185-201, \quad 2019 . \quad$ (DOI: https://doi.org/10.1016/j.autcon.2019.02.008)

[23] L. Bouhaya, O. Baverel and JF. Caron, "Optimization of gridshell bar orientation using a simplified genetic approach," Structural and Multidisciplinary Optimization Springer Verlag (Germany), Vol. 50, No. 5, pp. 839-848, 2014. (DOI: https://doi.org/10.1007/s00158-014-1088-9 )

[24] F. Tayeb, JF. Caron, O. Baverel and L. Du Peloux, "Stability and robustness of a $300 \mathrm{~m} 2$ composite gridshell structure," Construction and Building Materials, Vol. 49, pp. 926-938, 2013.

(DOI: https://doi.org/10.1016/j.conbuildmat.2013.0 $\underline{4.036}$ )

[25] F. Tayeb, "Simulation numérique du comportement mécanique non-linéaire de gridshells composés de poutres élancées en matériaux composites et de sections quelconques, " Ph.D. dissertation, Université Paris-Est, Marne la Vallée, 2015. (Online : http://www.theses.fr/2015PESC1067)
[26] L. Du Peloux, F. Tayeb, B. Lefevre, O. Baverel and JF. Caron, "Formulation of a 4Dof torsion/bending element for the formfinding of elastic gridshells," in Proceedings of IASS Annual Symposia, IASS 2015 Amsterdam Symposium: Future Visions, Amsterdam, The Netherlands, 17-20 August, 2015.

[27] C. Douthe, "Etude des structures élancées précontraintes en matériaux composites," Ph.D. dissertation, École des Ponts ParisTech, Marne la Valée, 2007. (Online: https://pastel.archives-ouvertes.fr/pastel$\underline{00003723 / \text { ) }}$

[28] M. R. Barnes, "Form-finding and Analysis of Tension Structures by Dynamic Relaxation," International Journal of Space Structure, Vol. 14, No. 2, pp. 89-104, 1999. (DOI: http://dx.doi.org/10.1260/0266351991494722 )

[29] L. Du Peloux, "Modeling of bending-torsion couplings in active-bending structures. Application to the design of elastic gridshells," Ph.D. dissertation, Structures, Université Paris Est, Marne la Valée, 2017. (Online: https://tel.archives-ouvertes.fr/tel$\underline{01757782}$ )

[30] R. Maia Avelino and O. Baverel, "Structural analysis of gridshells designed from singularities," in Proceedings of IASS Annual Symposia, IASS 2017 Hamburg Symposium, Hamburg, Germany, 25-28 September, 2017.

[31] B. Lefevre, C. Douthe and O. Baverel, "Buckling of elastic gridshells," J. IASS, Vol. 56, No. 3, pp-153-171, 2015.

[32] O. Baverel, C. Douthe and JF. Caron, "Nexorade: a structure for 'free form' architecture", in International Conference on Adaptable Building Structures. Eindhoven, Netherlands, 03-05 July, 2006.

[33] P. Marquis, A. Cersosimo and C. Douthe, "Building elastic gridshells from patches," in Proceedings of IASS Annual Symposia, IASS 2017 Hamburg Symposium, Hamburg, Germany, 25-28 September, 2017. 